\title{
A CRIANÇA COMO SUJEITO E COMO OBJETO ENTRE DUAS FORMAS DE INVESTIGAÇÃO DO ABUSO SEXUAL
}

\author{
THE CHILD AS A SUBJECT AND AS AN OBJECT BETWEEN \\ TWO KINDS OF INVESTIGATION OF THE SEXUAL ABUSE \\ EL NIÑO COMO SUJETO Y COMO OBJETO ENTRE DOS \\ FORMAS DE INVESTIGACIÓN DEL ABUSO SEXUAL \\ Luciana Piza* \\ Sonia Alberti**
}

\section{RESUMO}

Abordamos, neste artigo, o tratamento que vem sendo conferido ao tema do abuso sexual pela sociedade contemporânea e propomos uma contraposição a partir da teoria psicanalítica, especialmente no que nela se refere à sexualidade infantil. Partindo do princípio de que a criança é sujeito desejante, portanto sujeito de suas escolhas, conscientes ou inconscientes, interrogamos a atual tendência à sua objetalização no âmbito jurídico, psicológico e, até mesmo, em alguns textos psicanalíticos, e enfatizamos uma importante diferença entre o discurso jurídico e o psicanalítico. Como é sabido, este último distingue-se por conferir à criança o lugar de sujeito desejante, que pode estar subjetivamente implicado nas experiências de que toma parte, inclusive as sexuais. Baseamo-nos, para isso, fundamentalmente nas obras de Freud e de Lacan, mas também nas observaçóes de alguns psicanalistas que reafirmaram, nos últimos anos, uma posição ética da psicanálise diante do sujeito criança, com seu desejo e suas possibilidades de gozar, na contramão de uma lógica moralizante, normalizadora e higienista, que a objetaliza mais ainda.

Palavras-chave: inimputabilidade; responsabilidade subjetiva; abuso sexual; sexualidade infantil; psicologia jurídica.

* Universidade do Estado do Rio de Janeiro, Rio de Janeiro, RJ, Brasil.

** Universidade do Estado do Rio de Janeiro, Rio de Janeiro, RJ, Brasil. 


\section{Abstract}

This article discusses the treatment which is being given to the topic of sexual abuse by contemporary society and suggests a contrast from the psychoanalytic theory, especially as it refers to infantile sexuality. Assuming that the child is a subject of desire, therefore, subject to its choices, whether conscious or unconscious, we question the current tendency to relieve it's objectalisation in the legal, psychological and, even in some texts, psychoanalytic approaches and we emphasize an important difference between the juridical discourse and the psychoanalytic one. As we know, the latter distinguishes itself by giving the child the place of the desiring subject, which may be subjectively involved in the experiences in which it's taking part, including sexual ones. We rely for this, primarily, on the works of Freud and Lacan, but also on the observations that some psychoanalysts reaffirmed in recent years, on the ethical position of psychoanalysis facing the child as a subject, with its desire and jouissance possibilities, against a moralizing, normative and hygienist logic, which turns the child still more into an object.

Keywords: non imputation; subjective responsibility; sexual abuse; infantile sexuality; legal psychology.

\section{RESUMEN}

En este artículo se analiza el tratamiento que se le está dando al tema del abuso sexual por parte de la sociedad contemporánea y se propone contraponerle orientaciones que se encuentran en la teoría psicoanalítica, especialmente en lo que se refiere a la sexualidad infantil. Suponiendo que el niño es un sujeto de deseo, en consecuencia, sujeto de sus elecciones, ya sea conscientes o inconscientes, interrogamos la tendencia actual a su objetalización en los contextos jurídico, psicológico, e incluso, en algunos textos psicoanalíticos y hacemos hincapié en una diferencia importante entre el discurso jurídico y psicoanalítico. Como se sabe, este último se distingue por dar al niño el lugar del sujeto deseante, que puede ser subjetivamente involucrado en las experiencias en las que el participa, incluyendo las sexuales. Fundamentamos el desarrollo del texto, sobre todo, en las obras de Freud y de Lacan, pero no solo, también con el ayudo de las observaciones de algunos psicoanalistas que reafirmaron, en los últimos años, una posición ética del psicoanálisis frente al niño como sujeto, con su deseo y sus posibilidades de goce, contra una lógica moralizante, normativa e higienista que lo objectaliza más, aún.

Palabras clave: inimputación; responsabilidad subjetiva; abuso sexual; sexualidad infantil; psicología jurídica. 


\section{Introduçáo}

Ao reconhecer o fundamental papel desempenhado pela sexualidade infantil e ao privilegiar a fantasia de sedução em detrimento de sua ocorrência factual, Sigmund Freud fez surgir a dimensão da criança como autora de fantasias sexuais - portanto, como sujeito ativo em relação à sua sexualidade. Inobstante essas descobertas seculares, verificamos que, até os dias de hoje, há uma tendência por parte da sociedade em negar o desejo sexual na criança, localizando-o exclusivamente no adulto - especialmente no âmbito dos debates gerados por suposiçóes de abuso sexual. A questão que colocamos em discussão no presente artigo não é a da responsabilidade do adulto no abuso sexual - que é evidente e normalmente reconhecida como única - mas a da forma como é situada a criança no atual tratamento do assim chamado abuso sexual, na literatura e nas práticas tanto psicológicas quanto jurídicas. Questão que extrapola o contexto, pois retoma a polêmica que já figurava desde a orientação jurídica que se impunha no século XIX, quando, no Brasil, mulheres, crianças e índios passaram a ser criminalmente desresponsabilizados.

\section{A visão histórica da responsabilidade jurídica}

A primeira legislação penal brasileira - o Código Criminal do Império do Brazil - foi criada em 1830, inspirada no Código Penal Francês de 1810 (Tavares, 2004). Antes de 1830, crianças, jovens e adultos eram indistintamente punidos; a menor idade não constituía atenuante à pena. Somente a partir desse Código, jovens e crianças, além dos "loucos de todo gênero", passaram a receber tratamento diferenciado. "Art. 10. Também não se julgarão criminosos: $1^{\circ} \mathrm{Os}$ menores de quatorze anos" (Brasil, 1830, s/p.). Para esses, aplicava-se o sistema de discernimento, conforme explica a Promotora de Justiça Janine Borges Soares (s/data):

O Código fixou a imputabilidade penal plena aos 14 anos de idade [...] Entre sete e quatorze anos, os menores que agissem com discernimento poderiam ser considerados relativamente imputáveis, sendo passíveis de recolhimento às casas de correção, pelo tempo que o Juiz entendesse conveniente, contanto que o recolhimento não excedesse a idade de dezessete anos (Soares, s/data). 
Segundo a autora, no início do século XX um movimento internacional em prol dos direitos da criança reivindicou o reconhecimento de sua condição como distinta da do adulto. Esse movimento ganhou reforço com o advento de dois episódios importantes no cenário internacional - o Congresso Internacional de Menores, em Paris, em 1911, e a Declaração de Gênova de Direitos da Criança, que foi adotada pela Liga das Naçóes em 1924 constituindo-se o primeiro instrumento internacional a reconhecer a ideia de um Direito da Criança -, produzindo efeitos também no Brasil que, em 1921, instituiu um serviço de assistência e proteção à infância abandonada e delinquente e afirmou a exclusão de todo e qualquer processo penal para os menores de até 14 anos de idade. Já os menores entre 14 e 18 anos, se autores ou cúmplices de crime ou contravenção, seriam submetidos a processo especial (Soares, s/data).

Em 1927, consolidando as leis de assistência e proteção aos menores, foi estabelecido, segundo Soares (s/data), o primeiro Código de Menores do Brasil, a partir do qual o menor de catorze anos é eximido de qualquer processo penal e o maior de catorze e menor de dezoito anos, submetido a processo especial. A justificativa disso, por Alvarenga Netto (1941, citado por Soares, s/data) à época da vigência desse Código, é bastante interessante, pois, sustentando-se em psiquiatras de reconhecimento internacional, concluiu que um indivíduo com menos de 14 anos de idade não tem pleno desenvolvimento psíquico para assumir as responsabilidades de seus atos:

De fato, é matéria que não sofre contestação a falta de capacidade de imputação de menor dessa idade. Até os 14 anos, o indivíduo não tem o pleno desenvolvimento psíquico para que se possa responsabilizá-lo pelos delitos que cometer. A capacidade de imputação, escreve Regis (Précis de Psychiatrie), donde decorre a responsabilidade penal, é, como dizem Krafft-Ebing e Remond, o estado em que se encontra o indivíduo que é capaz de escolher entre a execução e a não execução de um ato qualificado criminoso e a de tomar uma resolução em um ou outro sentido. Os mais ardorosos partidários do livre arbítrio não se animam a atribuí-lo a uma criança de menos de 14 anos (Netto, citado por Soares, s/data, grifo nosso).

Ressalte-se o evidente descrédito, a partir de 1927, na possibilidade de escolha e de responsabilizaçáo de um menor de quatorze anos de idade, o que levou a um maior controle e vigilância destes. Vários estudos testemunham que o incremento dos saberes psicológicos na primeira parte do século XX tinha como 
fundamento o desenvolvimento, justamente, de medidas e métodos para o exercício do controle e vigilância (Alberti, 2003; Assunção, 2002).

Em 1940, o Código Penal Brasileiro - vigente até os dias atuais - fixou a imputabilidade penal aos menores de dezoito anos de idade, adotando o critério puramente biológico (idade do agente). Presumia - a partir de uma abordagem sem dúvida influenciada pelos discursos psicológicos então em franco desenvolvimento - que os menores de dezoito anos não possuem o desenvolvimento mental indispensável para serem responsabilizados nos termos da lei penal, diz Soares (s/ data).

No entanto, em 1984, na reforma do Código Penal, uma alteração no texto não passa despercebida: substituiu-se o termo "irresponsáveis" por "inimputáveis". Essa mudança, muito embora mantenha os mesmos princípios etários que se encontravam presentes à época da formulação do Código ainda vigente nos dias de hoje, é uma evidente releitura promovida pelos juristas. Ela deixa transparecer que talvez os juristas do final do século XX não fossem mais tão sectários quanto à responsabilização de um sujeito. Senão, vejamos.

Imputar, do latim imputare, significa "Atribuir (a alguém ou a alguma coisa) a responsabilidade de" (Michaellis, 2009). Conforme o Dicionário Jurídico (Direito Virtual, 2008) indicado pelo Guia de Direito Constitucional do Supremo Tribunal Federal - STF em seu site (Supremo Tribunal Federal, 2013), Imputabilidade "É a capacidade do indivíduo para ser responsabilizado penalmente" (Direito Virtual, 2008, grifo nosso). Já o Código Penal brasileiro diz:

\section{Da Imputabilidade Penal \\ Inimputáveis \\ Art. 26 - É isento de pena o agente que, por doença mental ou de- senvolvimento mental incompleto ou retardado, era, ao tempo da ação ou da omissão, inteiramente incapaz de entender o caráter ilí- cito do fato ou de determinar-se de acordo com esse entendimento. (Alterado pela L-007.209-1984) (Código Penal, 1940, grifo nosso).}

Há dois aspectos a ressaltar a partir dessas definiçóes. $\mathrm{O}$ primeiro diz respeito à ideia da isenção da pena a que se refere o Código Penal, à impossibilidade de se atribuir ou imputar ao menor uma responsabilidade penal porque, do ponto de vista jurídico, ele tem "desenvolvimento mental incompleto". Náo se trata da responsabilidade de uma forma geral, mas da responsabilidade penal. $\mathrm{O}$ outro aspecto que ressaltamos está relacionado ao fato de que a inimputabilidade se refere à impossibilidade de imputação, de atribuição pelo Outro 
jurídico de uma responsabilidade penal. Isso não quer dizer, necessariamente, que não haja responsabilidade do menor; quer dizer, tão somente, que a ele a responsabilidade penal não será imputada. Quer dizer que ele não pode ser objeto da atribuição de uma responsabilidade penal - ou seja, que ele não é responsabilizável pelo Outro jurídico. Todavia, isso não equivale a dizer que ele, como sujeito, não possa ser, ainda assim, responsável. $\mathrm{O}$ sujeito pode se reconhecer como responsável - subjetivamente responsável -, ainda que a lei o considere como penalmente irresponsabilizável, posto que o considere, a priori, incapaz de entender seu ato.

Entendemos que considerar alguém incapaz de ser penalmente responsabilizado não equivale a dizê-lo irresponsável. Essa é a mudança que queremos sublinhar na adoção do termo "inimputável”, no lugar do termo "irresponsável”, pois que deixa transparecer a ideia de que a responsabilidade, muito embora não possa ser atribuída ao menor do ponto de vista penal pelo Outro jurídico, pode, ainda assim, existir do lado do sujeito, pode ser assumida subjetivamente, se ele se considera responsável. $\mathrm{O}$ fato de a lei não poder responsabilizá-lo não implica que ele não possa reconhecer-se como responsável. Aliás, a recíproca também é verdadeira: não é porque a lei responsabiliza alguém de um delito que ele, como sujeito, necessariamente se responsabilizará. Responsabilidade jurídica e subjetiva não têm uma relação biunívoca. A responsabilização subjetiva não se confunde com a atribuição ou imputação de responsabilidade penal pelo Outro jurídico.

Se a Constituição Federal de 1988 elevou, por meio de cláusula pétrea, a inimputabilidade do menor de dezoito anos de idade à condição de princípio constitucional, e se o Estatuto da Criança e do Adolescente (1990) segue as mesmas premissas, mesmo se o menor é considerado juridicamente como irresponsabilizável, isso não implica a impossibilidade de o sujeito criança se responsabilizar. A diferença é sutil, mas nem por isso deixa de levar em conta a possibilidade de a criança ser vista como sujeito. Levantamos a hipótese de que os desenvolvimentos da psicanálise na articulação com outros saberes não são isentos de responsabilidade justamente nessa mudança, mesmo se a psicanálise não foi a única fonte na qual se instruíram os juristas para realizá-la. De todo modo, fica claro hoje que, de um lado, a lei, com razão, não imputa à criança ou ao menor a responsabilidade penal, o que, por outro lado, não mais impede que se possa considerá-la subjetivamente responsável a partir do que ela diz quanto à sua própria responsabilidade. Para tanto, evidentemente, o sigilo do consultório do psicanalista é o lugar mais adequado.

Para apreendermos o âmbito dessa hipótese, é necessário também avaliar as outras contribuiçôes de discursos psicológicos na questão. 


\section{A dessubjetivaçáo}

No século XX, com a criação das ciências humanas, o homem deixou de ser sujeito do conhecimento para ser seu objeto. Essa mudança engendrou uma desautorização do homem a falar de si mesmo na condição sujeito.

Faz-se necessário a priori desimputabilizar o homem e, se inicialmente o louco, o menor, a mulher, o índio, o analfabeto etc, passaram a não mais ser responsáveis perante a lei, seguiu-se toda uma escala de práticas que derrubou em definitivo a teoria do livre arbítrio (Alberti, 1984, p. 67).

Foi nesse âmbito que se inseriram as chamadas psicologias científicas, que marcaram a sua presença por meio do auxílio ao Estado na assunçáo da guarda dos menores, implicando, necessariamente, a desresponsabilização do próprio menor por seus atos.

O menor é uma categoria que surge ao mesmo tempo em que os saberes sobre o homem não mais o julgam capaz de ser autônomo. Aos poucos, o menor vai se tornando inapto a ter responsabilidades; ele surge a partir da infantilização do homem em geral, do homem que já não pode cuidar de si sozinho, quando então o 'menor' é o inapto por excelência. Para ele existe um projeto, seja estatal, familiar, pedagógico, no qual ele deve se inserir (Alberti, 1984, p. 79-80).

Nesse mesmo movimento, as práticas psicológicas trabalharam, ainda, no sentido de estabelecer uma classificação a ser aplicada aos menores segundo uma norma idealizada. Aqueles que dessa norma se desviassem deveriam ser transformados em menores normalizados. Joel Birman (2010) chama a atenção para o fato já mencionado por Michel Foucault de que se começou a tentar regular os anormais quando se visou à produção da normalidade e à prevenção de patologias. Desta forma constituiu-se, aliás, o fundamento do biopoder e da biopolítica, erigindo-se o trinômio: normal, anormal e patológico. E não só isso, mas tal poder e tal política também deram subsídios a que se consolidasse o imperativo da melhoria e da purificação da raça "posteriormente desdobrado no programa nazista” (Birman, 2010, p. 23). O afã classificatório vinha impregnado de ideais morais, que eram tomados como referência para a observação do caráter do menor e das deformidades a serem corrigidas, bem como para a estimulação das boas tendências. 
Nesse contexto, a masturbação infantil passou a ser objeto da vigilância e controle por ser tomada como promotora de doenças físicas e morais, e "uma verdadeira cruzada antimasturbatória entrou em cena, em nome da saúde e da moral infantil" (Birman, 2008, p. 12). A infância

passa a ser o fundamento da profilaxia do mau caráter, do crime, de más tendências, maus hábitos, comportamentos defeituosos, a fim de que, a partir dela [da infância], passem a triunfar a normalidade de um lado e a harmonia social do outro (Alberti, 1984, p. 74).

Ao discorrer sobre a psicanálise, as normas sexuais e o controle social, Birman, nessa mesma direção, afirma que "a construção de normas sexuais para o corpo infantil e o consequente controle social sobre o erotismo das crianças [...] se inscrevem nesta estratégia fundamental de medicalização do social" (Birman, 2000 , p. 42). Oito anos mais tarde, o mesmo autor ainda acrescenta que a "promoção do ideal da pureza infantil, no que concerne às questóes da sexualidade, seria a condição da saúde física e boa formação moral, tendo em vista a constituição de uma população saudável e o controle efetivo de futuras perturbações nervosas" (Birman, 2008, p. 13).

Se retomarmos o breve histórico da legislação que enfoca o menor, verificaremos que, do ponto de vista jurídico, a partir de 1927, crianças e adolescentes passaram a estar longe de serem tomados como sujeitos de atos nos quais seus desejos estariam implicados. Ao contrário, são tomados como puros objetos, desprovidos de capacidade de avaliar suas açóes e merecedores da proteção do Estado. Abre-se, aqui, outra questão, que é saber até onde há uma responsabilidade dos saberes psicológicos nessa abordagem jurídica.

A inimputabilidade no Direito acabou extrapolando suas fronteiras e entranhando toda a ideia que se tem, socialmente, da criança, que, em tempos hoje já quase imemoriais, podia ser identificada ao capeta, à coisa malvada. No máximo, conforme o discurso da ciência, fala-se em delinquência juvenil - sintagma que traz em seu bojo as ideias da antiga "medicina social" praticada no século XIX para tratar da sociedade e de seus miasmas (Machado, Loureiro, Luz, \& Muricy, 1978). Por outro lado, a criança é vista como vítima, o que se contrapóe à anterior imputabilidade. Até 1830, o menor era ou imputável ou vítima do demônio, em uma perspectiva religiosa. Quando esta última perdeu definitivamente terreno para a perspectiva científica, o menor passou a ser cada vez mais vitimado do desleixo, do abandono. 


\section{Denúncias e proteçóes}

Paradoxalmente, não raro se observa nos dias de hoje que as próprias ações de "proteção" podem, muitas vezes, produzir efeitos traumáticos para o sujeito, uma vez que nelas a subjetividade é negligenciada em nome de se "fazer justiça". Senão, vejamos: o que se pratica em alguns processos de denúncia e investigação policial/judicial de supostos casos de abuso sexual é, na realidade, um empuxo à investigação, com a dita finalidade de proteger crianças e adolescentes em situação de depoimento nos processos jurídicos, criando, no entanto, situaçóes em que a criança é duplamente objetalizada, levando-nos a questionar certos procedimentos. Um exemplo disso é o Projeto “Depoimento sem dano" (TJRGS, 2009).

Trata-se de um sistema de escuta judicial, idealizado por um Magistrado da Justiça da Infância e Juventude de Porto Alegre, que não somente recebeu destaque na $3^{\text {a }}$ Edição do Prêmio Innovare ${ }^{1}$, obtendo a Primeira Menção Honrosa (JIJERGS, 2006c), como está sendo adotado em outros estados, como Goiás, Acre e Rondônia (JIJERGS, 2007). O Projeto de Lei no 7.524/2006 apresentado ao Congresso Federal, propondo a alteração do Código de Processo Penal pela implementaçáo do Depoimento sem dano já foi aprovado na Câmara dos Deputados (JIJERGS, 2006b).

Segundo o Tribunal de Justiça do Estado do Rio Grande do Sul, o sistema "promove a proteção psicológica de crianças e adolescentes vítimas de abuso sexual e permite a realização de instrução criminal tecnicamente mais apurada" (JIJERGS, 2006a, grifo nosso). Nele são estabelecidos dois ambientes ligados por sistema de som e câmeras filmadoras, de modo que o depoimento da vítima é feito a Psicólogo ou Assistente Social que, sob monitoramento do Juiz, cumpre a função de inquiridor, teleguiado por um ponto eletrônico através do qual recebe instruçóes do Juiz. Este, junto ao promotor e ao advogado, permanece na sala ao lado, sem ser visto pela criança:

A iniciativa possibilita a realização de audiência, com criança molestada sexualmente [...] Em um dos recintos a vítima presta depoimento, reservadamente, a uma Psicóloga ou Assistente Social. No outro ambiente ficam o Juiz, o Advogado e outras partes. O magistrado faz as inquiriçôes por intermédio da técnica que se encontra com o menor. A vítima, dessa forma, não se expóe a outras pessoas... A forma empregada para se ouvir crianças é a mais humana e menos constrangedora (JIJERGS, 2003, grifos nossos). 
Cabe, contudo, interrogar, com alguns autores (Aleixo, 2008; Alves \& Saraiva, 2007; Conte, 2008): seria essa forma de escuta "mais humana e menos constrangedora"?

Levantamos algumas questóes em relação a essa metodologia:

1) Quem estaria sendo poupado do constrangimento, a criança ou o juiz? Ou seja, o depoimento seria sem dano para quem? A criança, nessa situação, não estaria muito mais no lugar de objeto do olhar e da vigilância de um Outro que não se mostra do que no lugar de sujeito? E, nesse caso, não poderíamos levantar a hipótese de que são finalmente o Juiz, o Promotor e os advogados que estariam sendo poupados de serem vistos, não a criança? E se ela, a criança, é na realidade o objeto visto, não se poderia contra-argumentar que na realidade há um gozo do olhar que viria da sala contígua e do qual a criança é puro objeto, objeto de gozo do Outro, portanto? Puro objeto novamente abusado?

2) Que lugar está sendo conferido ao psicólogo nesse dispositivo? Ele não está no papel de um terapeuta que, em sua função clínica, busca acompanhar seu paciente na tentativa de elaboração de uma experiência que pode ter sido traumática; tampouco é ele quem dirige a cena ou situação, pois é mero instrumento a serviço do Juiz. Este, do outro lado da sala, junto ao Promotor, advogados e outros, poupa-se do dano de um encontro que pode ser, para ele mesmo, traumático, na medida em que o confrontaria com o real do sexo exposto a céu aberto na fala da criança. Assim, poderíamos levantar a hipótese de que, na realidade, trata-se, nesse caso, de um segundo ato obsceno que está se desenvolvendo nessa situação: do outro lado da sala, no avesso do espelho, a criança constitui um puro objeto à mercê de um gozo escópico, a serviço do qual encontramos o Psicólogo que, por sua vez, também está destituído de sua função. Onde está o abuso, afinal? Qual é a verdade que esse discurso vela?

Até que ponto não estamos diante de um verdadeiro reality show em que o que há de mais íntimo para o sujeito é transformado em objeto do gozo escópico. Tal fato não é de todo extemporâneo numa sociedade do gozo escópico, como se observa inúmeras vezes, a partir da conceituação de Guy Debord (1997) da sociedade do espetáculo em que vivemos. Estaríamos nós vivendo uma situação em que até mesmo o Poder Judiciário é hoje atravessado por esse mesmo viés?

Além disso, ainda nesse questionamento, não estaríamos nós muito mais preocupados em imputabilizar alguém no dispositivo do Depoimento supostamente sem dano em lugar de abrir a possibilidade de fazer emergir algo de subjetivo acerca da experiência vivida pela criança? Até que ponto procurar extrair uma denúncia que culpabilize um suposto pedófilo, permitindo incriminá-lo e puni-lo, não seria uma forma de não se confrontar com as questóes que a se- 
xualidade coloca para todo ser humano em função de o tema, em si, já trazer, necessariamente, algo de inconfessável? Não seria, igualmente, uma forma de crer que a missão da Justiça teria sido cumprida sem que isso carreasse uma quota de angústia para algumas pessoas envolvidas com a investigação?

\section{A responsabilidade do psicanalista}

Se ao campo jurídico cabe a elaboração, proposição e sustentação de leis que visem à garantia de relaçóes civilizadas em sociedade - campo de atuação que deve contemplar dispositivos de proteção às crianças, quando isso se fizer necessário -, ao discurso psicanalítico interessa a realidade do inconsciente, psiquicamente construída e que constitui o sustentáculo do desejo do sujeito; interessa a posição subjetiva que a criança assume em suas relaçôes e a possível implicação de seu desejo nas experiências de que toma parte, inclusive as sexuais. Retomando o que dissemos acima, é justamente a partir do reconhecimento da implicação do desejo que o sujeito poderá vir a se responsabilizar subjetivamente por suas escolhas. Todo sujeito, adulto ou criança, tem a liberdade de se considerar subjetivamente responsável ou não responsável, mas a lei só poderá imputar responsabilidade penal ao maior de idade. Em outras palavras, trata-se de duas responsabilidades distintas: uma que é penal e que pode ou não ser atribuída a alguém pelo Outro jurídico; outra que é subjetiva e apanágio do sujeito: só ele próprio pode assumi-la, não cabendo imputação - independente de ele ser menor ou maior de idade, independente de como a lei o considera, capaz ou incapaz de responder por seus atos.

Note-se que uma importante diferença se destaca entre os campos jurídico e psicanalítico, na justa medida em que o desejo do sujeito se coloca em questão desejo que, se não interessa ao processo jurídico, ao processo analítico é central e indispensável. Assim, são campos que se revelam em sua interface, mas ao mesmo tempo, em suas especificidades e devidas distinçóes, o que nos convoca a analisar o abuso sexual de uma perspectiva outra, que não a social ou jurídica - trata-se da perspectiva do inconsciente.

Assim, indagamos: do lugar de psicanalista, como se posicionar diante de uma situação limite como o abuso sexual infantil, se levarmos em conta que a sua prática clínica está referida não a valores morais, mas à ética do desejo e que esta nunca faz a economia da angústia? $\mathrm{O}$ discurso psicanalítico - diferentemente de qualquer outro discurso, inclusive do jurídico - confere lugar central ao inconsciente, cuja realidade é sexual (Lacan, 1964/1998). Assim, o campo de 
investigação psicanalítica se sustenta em uma posição bastante singular, êxtimo à moral social civilizatória, contrário à negação da sexualidade infantil e da subjetividade da criança, de forma que em sua clínica o psicanalista já não se orienta pela doutrina higienista que, como vimos, é segregatória. Em consequência, chegam ao psicanalista não só os fatos do desejo como também os do gozo que póem o sujeito em uma relação de excesso com o corpo próprio e a moral social civilizada.

A dicotomia entre os excessos e a moral social civilizada foi estudada por Freud em inúmeros de seus textos. Em “O mal-estar na cultura”, Freud (1930 [1929]/2006) retoma o dito latino "o homem é o lobo do homem" e, com ele, esclarece que o que mais traz angústia ao ser humano é sua relação com os outros homens. Desde seus primeiros textos já observara que tal dicotomia é o grande conflito com o qual o sujeito deve se haver: de um lado, seu próprio prazer, de outro, o que lhe dita a sociedade visando sua própria preservação. A tensão criada entre ambas orientaçóes nunca se resolve em harmonia. A clínica psicanalítica nos ensina que esse é talvez o palco de maior sofrimento com o qual cada sujeito lida. A clínica psicanalítica também ensina que a única forma de a psicanálise se manter como discurso é colocando o sujeito no lugar daquele a quem o discurso se dirige, o que exige do psicanalista uma posição ética de jamais desconhecer o fato, em nenhuma hipótese, de que o sujeito em questão é o analisante.

Em todas as práticas que exercemos fora do consultório do psicanalista, quando estamos atravessados pela psicanálise, tal posição é condição sine qua non para identificarmos a presença desse discurso. Assim ocorre também quando nos encontramos com outras práticas e outros discursos, como é o caso do discurso jurídico na situação ora em análise.

Para a psicanálise, a criança que está em atendimento analítico é um sujeito como qualquer outro. $\mathrm{O}$ sujeito sempre tem suas particularidades e, em verdade, é absolutamente singular. Isso impede que o psicanalista faça uma regra de uma situação com a qual analisantes possam estar confrontados. Em função disso, não são poucos os casos que, a partir da clínica psicanalítica, nos exigem retomar a questão do abuso sexual de uma outra maneira Os sujeitos que são crianças e que viveram ou vivem situaçóes identificadas como sendo de abuso sexual não poucas vezes explicitam, em sessão, sua participação ativa na cena do abuso. Há mesmo casos em que relatos de crianças permitem verificar a maneira como chegaram a seduzir o adulto, como o caso de uma criança que admite ter forjado toda a cena, visando separar a mãe de um padrasto.

Essas situações não nos são relatadas em uma primeira entrevista, nem na segunda ou na terceira. Seus relatos são efeito de um trabalho que compete 
à criança quando em análise. E certamente a criança questiona seu analista. E é sobre esse aspecto que levantamos algumas observaçóes que seguem. Elas se justificam da perspectiva da clínica do psicanalista e, em princípio, não visam a questionar o discurso jurídico sobre o abuso sexual, mas, sim, introduzir questóes sobre a maneira pela qual se manifesta atualmente a opinião geral que criminaliza qualquer referência a um eventual relacionamento que um adulto possa ter para com uma criança quando está em jogo o desejo.

É necessário, antes de tudo, a nosso ver, verificar a diferença entre atos de pura violência, nos quais não se verifica a implicação do desejo da criança, e aqueles em que eventualmente tal desejo possa estar não apenas presente, mas mesmo numa relação recíproca para com aquele que, juridicamente, é identificado como agressor. As observaçóes que se seguem visam apontar para a diferença entre aquilo que o psicanalista testemunha em sua clínica e a generalização adotada na atualidade, em que a subjetividade da criança é sepultada pela perseguição segregadora aos assim designados pedófilos. No lugar de se ocupar da criança, a verificação de denúncias nas práticas de investigação acaba sendo a principal visada, em detrimento do que a criança possa querer investigar quanto à sua participação na cena.

A criança é desejante e age em função disso, o que não invalida que, perante a lei, quem responda sejam aqueles que por ela se assumem responsáveis.

Se, como preconiza Freud, o inconsciente é atemporal (Freud, 1915/2006b), o sujeito do inconsciente náo tem idade, de modo que, no que diz respeito à sexualidade, criança e adulto estão em pé de igualdade na relação com seus objetos: desejam-nos perversamente e deles gozam no afã de atingir a meta pulsional - a satisfação. Assim como o adulto, a criança assume, efetivamente, o lugar de sujeito em relação àqueles que toma como objeto, de modo que haverá situações em que a criança, na condição de sujeito, tomará um adulto como seu objeto sexual. $\mathrm{E}$, no que concerne a esse tipo de situação - note-se que não se trata de uma outra generalização, de uma outra possível configuração da cena sexual em que uma criança esteja envolvida -, a psicanálise assume, em relação ao discurso vigente, uma direção inversa, não desresponsabilizando subjetivamente a criança da cena traumática a que ela pode estar assujeitada por força da fantasia inconsciente.

Em verdade, a psicanálise não desresponsabiliza e, tampouco, responsabiliza a criança, posto que essa responsabilidade de que falamos é subjetiva - e não jurídica - e, dessa feita, é algo que não pode ser atribuído por outrem; pode, no máximo, ser assumido, pelo próprio sujeito. A assunção da responsabilidade subjetiva é apanágio do sujeito. Todavia, a diferença que o discurso do psicanalista pode produzir é a possibilidade de o sujeito vir a saber de seu desejo inconsciente e de 
seu gozo e, assim, assumir ativamente os atos nos quais tomou parte de modo a não se fixar na posição passiva que o discurso vigente parece promover.

Assim, a noção de responsabilidade subjetiva não se confunde com a noção de responsabilidade jurídica, na medida em que essa última diz respeito à imputação a alguém, por parte do Outro jurídico, da responsabilidade penal por um crime, ao passo que a primeira está referida à implicação do desejo do sujeito em suas escolhas e à possibilidade que lhe é dada, pelo trabalho de análise, de ele mesmo reconhecê-lo, assumi-lo como seu ao invés de imputá-lo a outrem; a possibilidade de o sujeito reconhecer a si mais como parte interessada do que como vítima. Nesse sentido, vitimizar o sujeito equivale a elidir a possibilidade de responsabilização subjetiva; equivale, segundo Colette Soler (2004, p. 48), a inocentá-lo da responsabilidade paradoxal pelo seu próprio desejo e por seus sintomas.

O reconhecimento, pela psicanálise, da implicação do sujeito em suas escolhas inconscientes exige que se o coloque no centro da questão sobre seu gozo - não no sentido de um saber sobre o gozo do outro, mas de um saber sobre o próprio gozo; não no sentido de responsabilizar o outro que dela goza, mas no sentido de se responsabilizar pelo seu próprio gozo. Não porque o outro não tenha responsabilidade, mas porque o sujeito que se dirige ao analista está implicado em suas escolhas. Eis onde o psicanalista pode questionar a maneira com que hoje a criança é tratada nas ditas açóes de proteção que, como vimos, podem ser muito mais traumáticas do que os eventuais abusos suspeitos.

Os psicanalistas Brandão Júnior e Ramos (2010), no artigo dedicado às contribuiçóes da psicanálise à escuta do sujeito em casos de abuso sexual, asseveram que, 'em nome de uma 'cientificidade' e do 'bem-estar' da criança, corre-se o risco de reforçar uma dimensão policial, de vigilância administrativa, e deixar de lado a implicação subjetiva de cada um" (Brandão Júnior \& Ramos, 2010, s/p). Em todo esse debate atual, a negação da implicação do sujeito criança nos atos dos quais toma parte é patente. E, nas diversas açóes de prevenção do abuso sexual e de proteção da criança feita vítima, engajam-se inclusive profissionais da área de saúde como psicólogos, psiquiatras e até psicanalistas.

\section{A criança como vítima}

Define-se com frequência o abuso sexual nos seguintes termos: "O abuso sexual ocorre através de práticas eróticas e sexuais impostas à criança ou ao adolescente pela violência física, ameaça ou indução de sua vontade" (Santos \& Dell'Aglio, 2010, s/p., grifo nosso). É evidente que, quando tal violência é imposta, não há dúvida quanto à impossibilidade de uma criança furtar-se a tal ação.

Psic. Clin., Rio de Janeiro, vol. 26, N.2, P. $63-85$, 2014 
A questão já não é a mesma quando definida assim: "O adulto seduz e impóe um tipo de ligação sigilosa sobre a criança, na tentativa de mascarar o abuso sexual" (Hisgail, 2007, p. 18). Nesse caso, é possível que essa ligação sigilosa venha ocorrendo por um tempo, e os relatos que conhecemos não deixam de aí implicar um interesse da criança. Quando lemos no mesmo autor que, do lado da criança, "o sofrimento psíquico derivado das situações de abuso sexual situa a vítima na posição de sobrevivente, da criança que se refugia de maneira precária no mundo interno, detendo um segredo sob o manto do silêncio" (Hisgail, 2007, p. 18), tais implicações da criança são completamente negadas, ela é totalmente vitimizada, e sugere-se que a criança sofre consequências psíquicas no mínimo preocupantes.

Uma outra forma ainda de abordar o tema identifica o uso da violência com a sedução, como se ambas fossem a mesma coisa: segundo França-Junior (2003), as práticas de abuso sexual "visam obtenção de prazer sexual dos adultos com uso de crianças, por meio da coerção privada com o uso da violência, posição hierárquica ou sedução" (França-Junior, 2003, s/ p.). Aqui já não há qualquer distinção entre uma situação na qual há violência - quando efetivamente a criança não tem como se defender - e que jamais poderá ser recíproca, até porque a força física não é equivalente, e a situação da sedução, na qual é possível, sim, haver sedução por parte da criança.

$\mathrm{Na}$ realidade, não há unanimidade na definição de abuso sexual (Mello, 2010, p. 74). Em função da multiplicidade de situaçóes a que provavelmente cada um desses autores se refere, colocar todas elas sob a mesma rubrica de abuso sexual é, talvez, a razão mais provável da generalização da qual a literatura é refém, alimentando, por sua vez, um tratamento generalizado do abuso sexual sem distinção do caso a caso.

No mesmo movimento de objetalização e vitimização da criança Pfeiffer e Salvagni afirmam que

Sentindo-se desprotegida pelo outro responsável [...] que permitiu a aproximação do abusador, insegura por imaginar que realmente não seria ouvida ou acreditada, envergonhada tanto pelo que passa, como pela sua impossibilidade de denunciar, por seu amor próprio reduzido e, ainda, ameaçada por aquele de quem habitualmente depende física e emocionalmente, ela [a criança] se cala, muitas vezes para toda sua vida (Pfeiffer \& Salvagni, 2005, s/p, grifos nossos).

As autoras partem do princípio de que a criança não faz escolhas, nem assume uma posição diante do outro que com ela pode ter estabelecido um jogo 
erótico - seja uma posição de aceitação ou de recusa, de qualquer forma uma posição ancorada em seu desejo. Para elas, o assim chamado abuso sexual consiste em uma forma doentia de violência, produzindo necessariamente traumas que seriam responsáveis por fazer da vitima alguém com predisposição a ulteriores sintomas psíquicos como depressão, ansiedade e até mesmo transtorno dissociativo de identidade ou transtorno de personalidade múltipla.

Isso porque, segundo Graça Pizá (2010), “[...] o abuso sexual é desigual. Não há acordos. Não é uma relação de prazer compartilhado" (Pizá, 2010, p. 20, grifo nosso). Ao contrário de reconhecer no desejo sexual infantil e no próprio gozo extraído pela criança (por mais paradoxal que possa parecer) a razão de sua participação nas cenas de abuso, essa autora, apesar de psicanalista, sustenta a posição de que a criança não tem capacidade para esquivar-se ou impedir o encontro sexual, de modo que paralisa, fica imóvel. Ela define essa imobilidade como "o afeto que impossibilita a reação de defesa da criança diante do perigo, da sedução, do pavor" (Pizá, 2010, p. 58). Sem dúvida, a situação traumática pode paralisar o sujeito. Resta saber o que é efetivamente traumático nessa história!

A clínica psicanalítica também nos ensina que o sujeito muitas vezes sofre por décadas a fixação em uma posição passiva diante de situaçóes por ele vividas. Manter o sujeito na posição de vítima em uma situação pode ser tão ou mais traumático do que a situação por ele experimentada. Mas, antes de avançarmos com essa questão, é importante ressaltar que tais abordagens psicanalíticas também têm seus efeitos no intercâmbio com outros saberes, certamente orientando outras abordagens, a jurídica, por exemplo.

\section{Participação e responsabilidade}

Observamos que antes do último decênio a posição não era exatamente essa no campo da psicologia. O psicólogo Tilman Furniss (1993) admite a "participação ativa no abuso sexual" (Furniss, 1993, p. 16) por parte da criança, mesmo se atesta que isso não equivale a reconhecê-la como responsável por isso. Diante do inequívoco sentimento de culpa manifesto pelas ditas vítimas do abuso, o autor chega a afirmar que "as crianças podem sentir-se responsáveis pelo abuso, embora, de fato, jamais possam ser responsáveis” (Furniss, 1993, p. 17):

A experiência da criança como participante no abuso explica como as crianças que sofreram abuso prolongado frequentemente expressam fortes sentimentos de culpa, independente do grau de cooperação e da vontade de participar do abuso. O sentimento de culpa da criança origina-se de seu 
senso equivocado de responsabilidade, que ela deriva do fato de ter sido uma participante no abuso (Furniss, 1993, p. 17, grifo nosso).

Eis, então, um autor que, em 1993, confirma o que a clínica ensina: a criança é participante, pode assumir sua responsabilidade na situação, e pode mesmo ter sentimento de culpa por ter chegado a viver a experiência por tempo prolongado. O que Furniss observa, no entanto, é que isso não quer dizer que ela seja, efetivamente, responsável; ao contrário, a própria noção da criança de responsabilidade seria equivocada - provavelmente porque ela desconhece o que seja uma responsabilidade jurídica, que não lhe é outorgada por se tratar de menor. Assim, o senso de responsabilidade que a criança revela, julgado pelo psicólogo Furniss como equivocado, pode indicar que se coloca em jogo uma outra responsabilidade que não a jurídica, uma outra responsabilidade que, ao contrário da jurídica, a criança não desconhece e que pode portar algo da verdade de seu desejo. Tal divisão entre o senso equivocado de responsabilidade da criança e a responsabilidade jurídica é própria desse campo do abuso sexual quando, de um lado, investigamos a situação como psicanalistas e, de outro, damos assessoria ao Poder Judiciário como psicólogos.

Se, como retoma Simone de Beauvoir (1970/2003), o inconsciente não tem idade, como se pode dizer que um sujeito - que só o é quando se responsabiliza no discurso - se engana de ser responsável? Lembremo-nos do que observa Freud (1923/2006) sobre a importância de o psicanalista levar a sério um sujeito que se declara peremptoriamente culpado sobre o que quer que seja! Permitamos-lhe dizer de sua falta no lugar de calá-lo ali onde exprime justamente o que lhe é mais íntimo.

É patente, portanto, o quanto a posição de Freud vai na contramão do que pudemos observar nessa breve revisão bibliográfica, em que se nega o desejo sexual da criança e, em alguns casos, sua implicação na cena do que convencionou-se chamar de abuso sexual. Brandão Júnior e Ramos (2010) observam que a atual "pregnância de um determinado modelo de atendimento construído ao longo do tempo e que repete, sem questionamento, as tentativas de adequação e normatização da infância, do sexo e das relaçôes entre os adultos e as crianças" (Brandão Júnior \& Ramos, 2010, s/p.) deve ser dialetizada com a psicanálise, que permite a assunção de uma posição outra, que faça "contraponto à ingenuidade e à incapacidade (plenas) atribuídas aos menores, crianças ou adolescentes, atribuição que é comum em algumas práticas de assistência e argumentação teóricas atuais" (Brandão Júnior \& Ramos, 2010, s/p.). É por compartilharmos esse ponto de vista que retomamos, em seguida, os fundamentos para uma abordagem diferente do tema. 


\section{A sexualidade infantil}

Voltemos a Freud e à escandalosa novidade trazida por ele em 1905 - a sexualidade infantil. Em seus Três ensaios sobre a teoria da sexualidade (1905/2006), artigo que até hoje ocupa lugar central em sua teoria, ele já denunciava os graves equívocos que se cometem historicamente ao se negar a existência da pulsão sexual na infância ou, quando sua ocorrência era inegável, tomá-la como raridade ou depravação precoce. Freud mostrava que, muito precocemente, desde o período de amamentação, a criança estabelece com seu corpo uma relação autoerótica, movida pelas pulsóes parciais que buscam satisfazer-se em atividades que tomam como objeto sexual quaisquer partes do corpo que foram, de algum modo, escolhidas e que, comportando-se como zonas erógenas, produzem prazer ao serem estimuladas. Ou seja, o que ele dizia ao mundo é que, desde a mais precoce idade da criança, ainda enquanto bebê, já se pode verificar a existência de prazer sexual, cuja importância far-se-á notar nos desdobramentos dessas experiências que, em consequência, são sexuais.

Segundo Freud, nada há de mais infantil do que a sexualidade que é, a rigor, perverso-polimorfa. Isso se dá por força de uma disposição originária universal da pulsão sexual, que exibe os germes de todas as perversões. Freud (1916-17[191517]/2006) verifica que essa disposição domina a atividade sexual infantil até que os diques anímicos como o asco, a vergonha e a moral, responsáveis por barrar os excessos sexuais, sejam erigidos. As crianças demonstram, a olhos vistos, endereçar seus primeiros apetites sexuais aos que lhe são mais próximos, como mãe, pai e irmãos, assim como deixam notar uma intensa busca de prazer a partir das zonas erógenas do próprio corpo. Desse modo, as crianças de tenra idade estão ainda livres das barreiras contra a busca de satisfação sexual nas relações incestuosas ou com pessoas do mesmo sexo, ou mesmo contra a satisfação pulsional em partes do corpo transformadas em zonas erógenas. Tais observaçóes levam a asseverar que a sexualidade é infantil e que a polimorfia perversa, ao contrário de ser um fato isolado na vida sexual da criança, está situada nos processos normais.

Esse caráter perverso-polimorfo é responsável por tornar todo e qualquer objeto admissível à criança - assim como a todo sujeito do inconsciente -, se for capaz de proporcionar-lhe a obtenção de prazer. Em "Pulsões e destinos da pulsão" (1915/2006a), Freud sublinha esse aspecto, atestando que nada é, na pulsão, tão variável quanto o objeto que, não sendo originariamente ligado a ela, só lhe é destinado por sua aptidão a proporcionar a satisfação. No atual contexto, cabe indagar: se a criança considera, para o fim de satisfazer a pulsão, todo e qualquer objeto, por que não tomar como objeto um adulto que a ela se insinue 
eroticamente, num jogo de sedução do qual ela pode extrair prazer, na tentativa de satisfazer a pulsão? Ao verificar que a criança inclui as outras pessoas como seus objetos, a psicanálise abre a possibilidade para tal questão, senão vejamos: “[...] também a vida sexual infantil, apesar do império que exercem as zonas erógenas, mostra componentes que desde o começo envolvem outras pessoas como objetos sexuais" (Freud, 1905/2006, p. 174).

Tais outras pessoas, como visto, são aquelas mais próximas da criança, o que necessariamente leva à articulação do tema com o complexo de Édipo, conceituado como o elo que enlaça sexualidade infantil e fantasia. Ao se dedicar ao estudo sobre a fantasia e a sua importância como realidade psíquica do sujeito, Freud (1908/2006) indica que àquilo que originariamente constituía um ato essencialmente autoerótico (masturbação infantil) - sem conteúdo ideativo, dirigido às zonas erógenas, com a finalidade única de satisfazer as pulsóes parciais - viria incorporar-se, a partir da relação edípica, uma ideia vinculada ao amor objetal, impregnada de desejo. Assim, as atividades sexuais infantis passam a ter como enredo o amor edípico. Lima e Pollo (2005) lembram que a descoberta freudiana do complexo de Édipo levou à constatação de que sua vivência engendra fantasias e impulsos sexuais e, em relação a eles, a criança está longe de ser um objeto passivo:

Esses impulsos e fantasias, como bem sabemos, tomam preferencialmente como objeto os adultos que desempenham as funçóes materna e paterna. Tal constatação [...] representou uma verdadeira ruptura na compreensão da sexualidade humana, primeiramente, ao demonstrar a criança como um sujeito ativo do desejo, não necessariamente um ser passivo diante dos adultos (Lima \& Pollo, 2005, p. 560, grifos nosso).

A psicanálise é um discurso que impóe situar no lugar do sujeito aquele a quem o psicanalista se dirige. "Por nossa posição de sujeito, somos sempre responsáveis" (Lacan, 1966/1998, p. 873). Desse modo, não há como nos furtarmos, como psicanalistas, a verificar uma criança ou um adolescente nosso paciente como sujeitos situados enquanto desejantes na cena que nos apresentam, seja ela qual for. Isso implica, pois, prescindir de uma visão moralizante e normatizante e levar em conta o caráter perverso originário e constitutivo da sexualidade.

Acrescentamos, com Joel Birman (2010), que a teoria freudiana acerca da sexualidade, fundamentalmente relacionada à escrita e à decifração das fantasias eróticas, vai na contramão de todo e qualquer positivismo cientificista, que pretende a normalização do sexual: "ao desatrelar a sexualidade do registro biológico e 
inscrevê-la nos registros da pulsão e do fantasma, a psicanálise interrogou o processo de normalização do erotismo legitimado pela sexologia” (Birman, 2010, p. 25).

Tal orientação distancia a posição do psicanalista diante da questão sobre o abuso sexual de toda metodologia de desresponsabilização subjetiva da criança. Assim, aplaudimos a modificação do Código Penal de 1984, que substituiu o termo no qual se lia que a criança não era responsável pelo termo "inimputabilidade". Se o texto da lei os distinguiu, a prática e o exercício dela, no cotidiano da sociedade brasileira, ao contrário, os amalgama cada dia mais! O fato de a criança ser inimputável, tendo em vista, fundamentalmente, sua imaturidade tanto física quanto psíquica, que não lhe dá meios de defesa os mais primários diante da insistência de um adulto, não a torna, no entanto, menos implicada enquanto sujeito do desejo. Mas o que se observa nos dias de hoje é sua total vitimização, inclusive perante os próprios meios de verificação de uma denúncia de abuso sexual, que muitas vezes a objetaliza até mais do que o próprio fato da sedução.

\section{Referências}

Alberti, S. (1984). Direito do menor: a contribuição dos saberes psicológicos. In F. A. M. Rosa (Ed.). Direito e mudança social (pp. 65-81). Rio de Janeiro: OAB RJ/UERJ.

Alberti, S. (2003). Crepúsculo da alma. A psicologia no Brasil no século XIX. Rio de Janeiro: Contra Capa Livraria.

Aleixo, K. C. (2008). A extração da verdade e as técnicas inquisitórias voltadas para a criança e o adolescente. Revista Psicologia Clínica, 20(2), 103-111.

Alves, E. O., \& Saraiva, J. E. M. (2007). Depoimento "sem dano"?. Recherche, Conseil et Formation. Recuperado em 7 outubro, 2012, de <http://www.antigone-formation.com/racine/ article.php3?id_article $=104>$.

Assunção, M. M. S. (2002). A psicologia da educação e a construção da subjetividade feminina. (Tese de Doutorado. Programa de Pós-graduação da Faculdade de Educação, Universidade Federal de Minas Gerais, Minas Gerais, MG).

Beauvoir, S. de. (2003). A velhice. Rio de Janeiro: Nova Fronteira. (Trabalho original publicado em 1970).

Birman, J. (2000). Uma erótica da ambiguidade? Sobre psicanálise, normal sexual e controle social. Cadernos de Psicanálise, 16(19), 33-55.

Birman, J. (2008) Entre o público e o privado. Sexos - a trama da vida, 3, 6-13.

Birman, J. (2010). A sexualidade na berlinda. In M. R. Prata (Ed.). Sexualidades (pp. 15-26). Rio de Janeiro: Contra Capa Livraria.

Psic. Clin., Rio de Janeiro, vol. 26, N.2, P. $63-85$, 2014 
Brandão Júnior, P., \&Ramos, P.L. (2010). Abuso sexual: do quese trata? Contribuições da psicanálise à escuta do sujeito. Psicologia Clínica, 22(1). Recuperado em 03 outubro, 2010, de <http:// www.scielo.br/scielo.php?script=sci_arttext\&pid=S0103-56652010000100005\&lng=pt\& $\mathrm{nrm}=\mathrm{iso} \& \mathrm{t} \operatorname{lng}=\mathrm{pt}>$.

Brasil. (1830). Código Criminal do Império do Brazil - Lei de 16 de dezembro de 1830. Recuperado em 20 Janeiro, 2010, de <http://www.planalto.gov.br/ccivil_03/Leis/LIM/LIM-1612-1830.htm>.

Brasil. (1940). Código penal-Decreto-Lei n. 2848, de 7 de dezembro de 1940. Conjunto de leis de disposiçóes relativas ao que vem a ser crime perante a Nação e as penas consequentes. Recuperado em 20 janeiro, 2010, de <http://www.planalto.gov.br/ccivil_03/decreto-lei/ del2848compilado.htm>.

Brasil. (2004). Constituição da República Federativa do Brasil de 1988. São Paulo: Saraiva.

Conte, B. S. (2008). Depoimento sem dano: a escuta da psicanálise ou a escuta do direito? Psico, 39(2), 219-223.

Debord, G. (1997). A sociedade do espetáculo. Rio de Janeiro: Contraponto.

Direito Virtual. (2008). Dicionário Jurídico. Recuperado em 03 de junho, 2013, de <http:// www.direitovirtual.com.br/?section=dicionario_portugues-inicial\&termo=I $>$.

Estatuto da criança e do adolescente. (1990). Lei Federal N. 8069 de 13 de julho de 1990. Recuperado em 08 abril, 2010, de <http://www.planalto.gov.br/ccivil_03/Leis/L8069.htm>.

França-Junior,I.(2003).Abusosexualnainfância:compreensãoapartirdaEpidemiologiaedosDireitos Humanos. Interface (Botucatu), 7(12). Recuperadoem 10novembro, 2010, de <http://www. scielo.br/scielo.php?pid=S1414-32832003000100003\&script=sci_abstract\&tlng=pt $>$.

Freud, S. (2006). Tres ensayos de teoría sexual. In S. Freud. Obras Completas, v. VII. Buenos Aires: Amorrortu Editores. (Trabalho original publicado em 1905).

Freud, S. (2006). Las fantasías histéricas y su relación con la bisexualidad. In S. Freud. Obras Completas, v. IX. Buenos Aires: Amorrortu Editores. (Trabalho original publicado em 1908).

Freud, S. (2006a). Pulsiones y destinos de pulsión, In S. Freud. Obras Completas, v. XIV. Buenos Aires: Amorrortu Editores. (Trabalho original publicado em 1915).

Freud, S. (2006b). Lo inconciente. In S. Freud. Obras Completas, v. XIV. Buenos Aires: Amorrortu Editores. (Trabalho original publicado em 1915).

Freud, S. (2006). Conferencias de introducción al psicoanálisis. In S. Freud. Obras Completas, v. XV e XVI. Buenos Aires: Amorrortu Editores. (Trabalho original publicado em 1916-17 [1915-17]).

Freud, S. (2006). El yo y el ello. In S. Freud. Obras completas, v. XIX. Buenos Aires: Amorrortu Editores. (Trabalho original publicado em 1923).

Freud, S. (2006). El malestar en la cultura. In S. Freud. Obras completas, v. XX. Buenos Aires: Amorrortu Editores. (Trabalho original publicado em 1930[1929]). 
Furniss, T. (1993). Abuso sexual da criança: uma abordagem multidisciplinar. Porto Alegre: Artes Médicas.

Hisgail, F. (2007). Pedofilia: um estudo psicanalitico. São Paulo: Iluminuras.

Justiça da Infância e da Juventude do Estado do Rio Grande do Sul - JIJERGS. (2003). Vitimas de abuso sexual precisam de abordagem cuidadosa. Recuperado em 20 outubro, 2010, de <http://jij.tj.rs.gov.br/jij_site/jij_site.home>.

Justiça da Infância e da Juventude do Estado do Rio Grande do Sul - JIJERGS. (2006a). "Depoimento Sem Dano" permite instruçâo criminal mais apurada. Recuperado em 13 agosto, 2010, de <http://jij.tj.rs.gov.br/jij_site/jij_site.home>.

Justiça da Infância e da Juventude do Estado do Rio Grande do Sul - JIJERGS. (2006b). Sistemática do projeto "Depoimento sem Dano" poderá ser recomendada em lei nacional. Recuperado em 13 agosto, 2010, de <http://jij.tj.rs.gov.br/jij_site/jij_site.home>.

Justiça da Infância e da Juventude do Estado do Rio Grande do Sul - JIJERGS. (2006c). Magistrado recebe menção honrosa na cerimônia do Prêmio Innovare. Recuperado em 26 agosto, 2010, de <http://jij.tj.rs.gov.br/jij_site/jij_site.home>.

Justiça da Infância e da Juventude do Estado do Rio Grande do Sul - JIJERGS. (2007). Convênio repassará recursos para Depoimento sem Dano. Recuperado em 13 agosto, 2010, de <http://jij.tj.rs.gov.br/jij_site/jij_site.home>.

Lacan, J. (1998). O seminário, livro 11: os quatro conceitos fundamentais da psicanálise. Rio de Janeiro: Jorge Zahar. (Seminário original de 1964).

Lacan, J. (1998). Subversão do sujeito e dialética do desejo no inconsciente freudiano. In J. Lacan. Escritos (pp. 807-841). Rio de Janeiro: Jorge Zahar. (Original publicado em 1966).

Lima, S. S., \& Pollo, V. (2005). A violência sexual em nossos dias: questôes para a psicanálise. Psicologia: ciência e profissão, 2(4), 558-571.

Machado, R., Loureiro, Â., Luz, R., \& Muricy, K. (1978). Danação da norma: a medicina social e constituição da psiquiatria no Brasil. Rio de Janeiro: Graal.

Mello, L. C. A. (2010). Exploração social comercial de crianças e adolescentes: o estado da arte nas produçôes acadêmicas em psicologia. (Dissertação de Mestrado. Curso de Pós-graduação em Psicologia, Universidade Federal do Rio Grande do Norte, Natal, RN).

Michaellis. (2009). Dicionário de Português Online. Recuperado em 02 de junho, 2013, de $<$ http://michaelis.uol.com.br/moderno/portugues/index.php?lingua=portugues-portugues \&palavra=imputar $>$.

Pfeiffer, L., \& Salvagni, E. P. (2005). Visão atual do abuso sexual na infância e adolescência. Jornal de Pediatria, 81(5). Recuperado em 10 novembro, 2010, de <http://www.scielo.br/ scielo.php?pid=S0021-75572005000700010\&script=sci_arttext $>$.

Pizá, G. (2010). Afetosecrectos, o vocabulário. São Paulo: Imprensa Oficial do Estado de São Paulo. 
Santos, S. S., \& Dell'Aglio, D. D. (2010). Quando o silêncio é rompido: o processo de revelação e notificação de abuso sexual infantil. Psicologia Social, 22(2). Recuperado em 10 novembro, 2010, de <http://www.scielo.br/pdf/psoc/v22n2/13.pdf>.

Soares, J. B. (s/data). A construção da responsabilidade penal do adolescente no Brasil: uma breve reflexão histórica. Ministério Público do Estado do Rio Grande do Sul. Recuperado em 10 janeiro, 2010, de <http://www.mp.rs.gov.br/infancia/doutrina/id186.htm>.

Soler, C. (2004). Trauma e fantasia. Stylus Revista de Psicanálise, 9, 45-59.

Supremo Tribunal Federal (2013). Guia de Direito Constitucional. Recuperado em 03 de junho, 2013, de <http://www.stf.jus.br/portal/cms/verTexto.asp?servico=bibliotecaConsulta ProdutoBibliotecaGuiaDC\&pagina=dicionariojuridico $>$.

Tavares, H. G. M. (2004). Idade penal (maioridade) na legislação brasileira desde a colonização até o Código de 1969. Revista Jus Navigandi. Recuperado em 13 janeiro, 2010, de <http://jus2.uol.com.br/doutrina/texto.asp?id=5958>.

Tribunal de Justiça do Estado do Rio Grande do Sul - TJRGS (2009). Depoimento sem dano. Recuperado em 18 março, 2011, de <http://www.mp.rs.gov.br/areas/infancia/arquivos/depoimentosem_dano.pdf>.

\section{Nota}

${ }^{1} \mathrm{O}$ objetivo do Prêmio Innovare é identificar, premiar e disseminar práticas inovadoras realizadas por magistrados, membros do Ministério Público estadual e federal, defensores públicos e advogados públicos e privados de todo Brasil, que estejam aumentando a qualidade da prestação jurisdicional e contribuindo com a modernização da Justiça Brasileira. Saiba mais: $<$ http://www.premioinnovare.com.br/institucional/o-premio/>.

Recebido em 12 de novembro de 2012 Aceito para publicação em 05 de agosto de 2013 